\title{
Customer Satisfaction Towards Self-Service Kiosks for Quick Service Restaurants (QSRs) in Klang Valley
}

Zurena@Rena Shahril, Hidayatul Aisyah Zulkafly, Nurliza Suzlina Ismail, Nur Umizatul Nasuha Md Sharif

To Link this Article: http://dx.doi.org/10.6007/IJARBSS/v11-i13/8502

DOI:10.6007/IJARBSS/v11-i13/8502

Received: 06 November 2020, Revised: 28 November 2020, Accepted: 16 December 2020

Published Online: 28 January 2021

In-Text Citation: (Shahril et al., 2021)

To Cite this Article: Shahril, Z., Zulkafly, H. A., Ismail, N. S., \& Sharif, N. U. N. M. (2021). Customer Satisfaction Towards Self-Service Kiosks for Quick Service Restaurants (QSRs) in Klang Valley. International Journal of Academic Research in Business and Social Sciences, 11(13), 54-72.

Copyright: (c) 2021 The Author(s)

Published by Human Resource Management Academic Research Society (www.hrmars.com)

This article is published under the Creative Commons Attribution (CC BY 4.0) license. Anyone may reproduce, distribute, translate and create derivative works of this article (for both commercial and non-commercial purposes), subject to full attribution to the original publication and authors. The full terms of this license may be seen

at: http://creativecommons.org/licences/by/4.0/legalcode

Special Issue: Beyond 2021 and COVID-19 - New Perspective in the Hospitality \& Tourism Industry, 2021, Pg. 54 - 72 


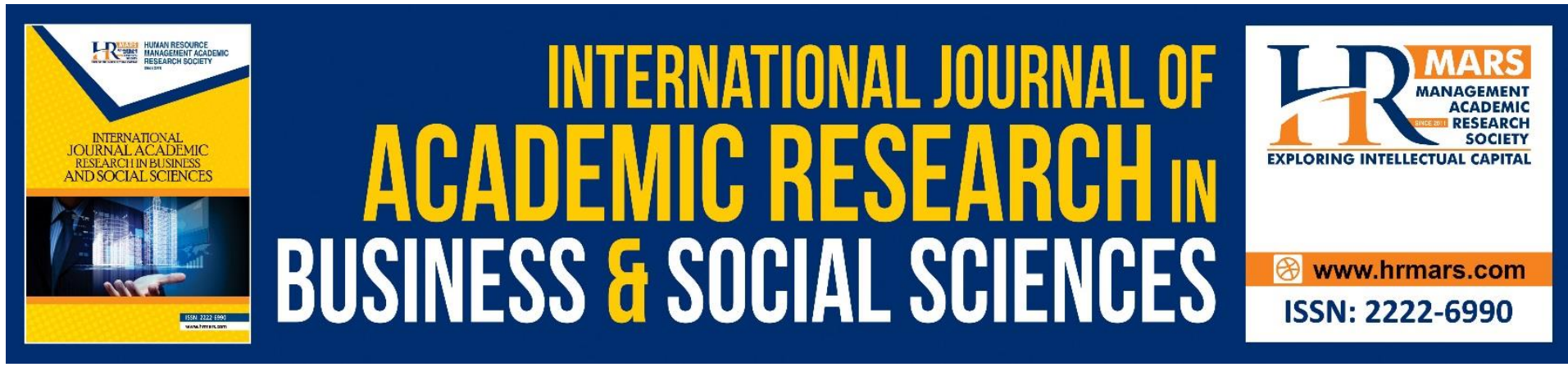

\title{
Customer Satisfaction Towards Self-Service Kiosks for Quick Service Restaurants (QSRs) in Klang Valley
}

\author{
Zurena@Rena Shahril, Hidayatul Aisyah Zulkafly, Nurliza \\ Suzlina Ismail, Nur Umizatul Nasuha Md Sharif
}

Faculty of Hotel and Tourism Management, Universiti Teknologi MARA, Selangor, Malaysia.

\begin{abstract}
The growth of technologies is transforming countless economic or business activities. This situation is offering greater competence and expediency to customers and businesses, and the evolution in technology without an exception of restaurant industry has played a vibrant role in changing customers' satisfaction. towards self-service kiosk in Quick Service restaurants (QSRs). Thus, the application of technology in businesses is a worthy gain in attracting the customers since most customers nowadays are technology-oriented. The technology based self-service kiosk allows customers to facilitate the ordering process without or with minimal help from service providers. There are four key factors of selfservice kiosk that may impact the customer satisfaction specifically ordering speed, convenience, menu design and accuracy order in this study setting. Therefore, this study is to examine the relationship between features of self-service kiosk and customer satisfaction. A quantitative cross-sectional research design was chosen particularly in QSRs in Klang Valley. The results indicated that customer satisfaction was directly influenced by ordering speed, convenience, menu design and order accuracy towards self-service kiosk for QSRs. These findings provide theoretical and practical implications for future studies and offers concrete direction for other business entities to consider adopting the self-service kiosk in their commercial operations.
\end{abstract}

Keywords: Self-service Kiosks, Quick Service Restaurants, Ordering Speed, Convenience, Menu Design, Accuracy Order, Customer Satisfaction.

\section{Introduction}

Food service industry is one of the largest industries in the world. In 2018, Sawe stated that in Canada, the service industry is the first largest industry and it contributed as the main drive for Canada's economy. Plecher (2020) also pointed out that the service sector dominated Malaysia's employment where almost 62 percent of the labour force is working in this sector. The food service sector includes Quick Service Restaurants (QSRs), family restaurants, cafeterias, fine dining, bars, themed restaurants, and ethnic restaurants. Every food service sector varies in their offering and appearances including service that depends on their 
concepts of restaurant.

In the food service business, there are many competitions in the industry. The food service operators have been applying aggressive marketing strategies to draw new customers and maintain regular customers to compete in this industry. One of the ways that food service operators have chosen is through the introduction of technology in the industry. Over the last few decades, the food service industry has changed drastically from writing the order on the paper to a digital POS system. The technology advancement which had been introduced in the food service industry consists of the internet ordering, digital payment, reservations apps, tablets menu order, or self-service kiosks. Quick service restaurant (QSR) such as McDonald is one of the food service sectors that started the adoption of technology in their services. Quick service restaurants (QSRs) aggressively adopted self-service kiosks to serve their customer efficiently and effectively. Self-service kiosk is one of the technologies that allow customers to facilitate the ordering process without or with minimal help from service providers.

However, some customers are still reluctant to use self-ordering technology especially the generation who comes from 'baby boomer'. They still prefer to communicate with the service providers and might not have satisfied with this technology advancement (Rastegar, 2018). In many studies on service quality, waiting time is one of the most important aspects to inspect the perceived service quality and gaining customers' satisfaction. In 2015, Kokkinou and Cranage said that to increase the customers' perception and perceived quality of the service, restaurant businesses have to focus on the reduction of actual waiting-times through the presence of self-ordering machines at their stores. Customer satisfaction and perceived service quality are strongly influenced by actual waiting times. Kokkinou and Cranage (2015) also stated that the service level correspondingly linked with customer satisfaction. Apart from that, service level was also found to be associated with waiting time performance. Therefore, both waiting times and service levels are considered as related components to gain customer satisfaction.

In 2018, Rastegar elaborated that some customers are still reluctant to use the self-service kiosks because they prefer to interact with the service providers due to lack of knowledge on technology. They would not be able to use the machine properly without guidance from the staff. Fast food restaurant chains need to put the workers at the nearer self-service kiosks to make it easier for elderly customers since they are not considered as tech-savvy as the youngsters. If the workers are not placed at the self-service kiosks, the customers would have difficulties on choosing the meal plans. Besides, the customers also feel doubtful about the security of the machine as it requires them to share their personal information or data such as their debit card password in order to perform the transaction.

Additionally, in the selection of food, the menu design must be attractive, instructive and informative. According to Pavesic (2005), the menu is normally the most crucial selling instrument and internal marketing platform to a Quick Service Restaurant (QSR), to market their foods to the customers. Hence, the restaurant owner must be creative and well known with the menu design that will make customer feel comfortable to use. The colour, the size and font of the menu in self-service kiosk must also be suitable and perfect for them to read. 
A well-designed menu can communicate and entertain the customers as well as promote the foods prepared at the Quick Service Restaurants (QSRs). According to a report by Rastegar (2018), the self-service kiosks can minimize errors and increase customer satisfaction by facilitating customized ordering. In addition, a visual recap of a customer's order increases the accuracy and puts the liability for the customers. Self-service kiosks allow the customers to place and pay for their orders easily, swiftly, and accurately.

\section{Literature Review \\ Self Service Kiosks}

Rastegar (2018) stated that self-service kiosks are one of the extensively used self-service technology (SST). Kokkinou and Cranage (2015) defined self-service technology (SST) as a technological interface that allows customers to produce service without a service employee's involvement. In other words, self-service technology (SST) is "a technology that was provided by the organization specifically to enable customers to engage in self-service behaviour replacing the role of frontline employees" (Robertson, McDonald, Leckie, \& McQuilken, 2016, p. 92).

Self-service kiosks are one of the self-service technologies (SST) that has a common feature in certain segments of the hospitality industry. Self-service kiosks have been used regularly in hospitality and tourism industry; in airlines as self-service check-in kiosks and currently used as a new movement in restaurants. Rastegar (2018) also described "self-service kiosk is a machine with a large touch screen that enables customers to order food, customize their menu items and even pay their bill without interacting with employees" (p. 4). In Malaysia, self-service kiosks are widely used in quick service restaurants (QSRs) especially in McDonald's. In 2019, Tariq reported that Kentucky Fried Chicken (KFC) also launched their first self-service kiosks in Klang Valley. The implementation of self-service kiosks helps quick service restaurant (QSR) reduces labour cost, improve productivity and increase profit ("Benefits of Self-Service Kiosks in QSR and Restaurants - Frank Mayer," 2020). Rastegar (2018) believed that the adoption of self-service kiosks helps to reduce waiting time, more convenient transactions, improve the menu design, and increase accuracy order.

Generally, self-service kiosks provide a new convenient service delivery service to customers. Yieh, Chen, and Wei (2012) concluded that the traditional ordering process that requires the waiters to write down the orders to the kitchen, serve the dishes, and finally prepare the bills is now more convenient and effective with Self Service Technology (SST). However, certain customers still hesitant to use self-service technology (SST) due to their concern on having the technical mistakes while using this technology and disclosing personal information or data such as a debit card password for the payment (Rastegar, 2018). Thus, the restaurant operator needs to continuously analyse the customer's satisfaction regarding this technology and make improvements if needed.

\section{Customer Satisfaction}

In achieving customer satisfaction, it is complicated just to understand and identify customers' needs and expectations. Ograjensek and Gal (2019) claimed that, because of this obstacle, the company needs to study about what to measure and how to collect the data to ensure their customers' needs and expectations can be satisfied. Therefore, the researchers 
decided to use certain things as dimensions namely the revisit and recommend intention to measure customer satisfaction. Ograjensek and Gal (2019) also stated that customer satisfaction and perceived service quality as well as customer experience and customer engagement refer to the concept that can be significant to customers' reactions to products or services. Customers can be defined as a person who buys goods and services as well as the ultimate justification for any business especially restaurants to survive in the market. Meanwhile, satisfaction can be seen or achieved when the customers delighted with the products and services and have no complaints. Generally, perceived service quality and customer satisfaction are two different things. On the contrary, they are connected to the customers' perceptions of a product or service.

Abdullah, Hamir, Nor, Krishnaswamy, and Rostum (2018) showed that revisit is an individual decision to visit the same place or the service provider again. The authors also stated, this satisfaction somehow brings out positive emotions in the customers and they are extremely give remarkable feedback to the service providers. Furthermore, there is a high possibility for the customers who received wonderful and notable experience from the restaurants they visited to spread the information among their friends. This positive word of mouth or recommendations undoubtedly will draw other people to visit the restaurants (Yong, Siang, Lok \& Kuan, 2013).

\section{Ordering Speed}

Ordering speed is one of the ways to measure the effectiveness of the technology. There are two dimensions in this ordering speed which are the waiting line and speed of the transaction. The waiting line normally refers to the customers who personally wait in queues before being served by any service provider. One of the important determinants in measuring a betterwaiting line is the minimum waiting time to receive the service. Generally, the delays in service will lead to negative upshots from the customers. Thus, this technology may reduce the time waiting at the counter and fasten the transaction. Kokkinou and Cranage (2015) proved that shorter waiting time or faster service appears to influence customers' decision to use the self-ordering technology. People nowadays want to have faster service instead of waiting to be served. With this technology, they just need to order their preference using this self-ordering kiosk and pay immediately at the machine. Ismail and Shokor (2016) claimed that the effectiveness of the system can only be determined when one server serves one customer at a time. This is overwhelmingly problematic for the fast food restaurant in recent years as the customer needs to wait for the next available cashier without any other option in this particular system.

\section{Convenience}

Convenience in this context refers to the way people would react towards technologies. Convenience in technologies allows people to use it for an easier lifestyle. Nowadays, technology makes everything easier as it is all about the control of your fingertips. Kimes (2011) mentioned that in order to increase customer satisfaction, it should be incorporated with the perceived convenience of a self-service system. The customers will feel more satisfied to utilize a self-ordering machine instead of paying at the counter. Convenience is divided into two dimensions which are less communication and ease of payment. It is believed that perceived convenience is associated with the access convenience and transaction 
convenience (Kimes, 2011). This kind of ordering system provides a clear image and detailed information about the product offered by the quick service restaurant (QSR) itself. All the menus and pricing should be stated in the machine provided. Thus, it will help the customers to choose their orders and reduce the error when they are placing their orders by themselves. It was proved by Dabholkar as cited in Kimes (2011), the use of this ordering system can overcome the challenges and meet the communication gap between the customers and service providers. Customers and other waiting customers will appreciate if they do not have to wait for the service providers to take their order, and this can encourage them to use the self-service kiosk. Therefore, the service providers do not have to wait for their customers to make an order and they can just focus on doing some other operations at the back of the premises. Self-service kiosks can also make the customers feel excited to use the machine since they do not have to wait for their orders being taken by the service providers which could take a whole lot of time.

Apart from that, these self-service kiosks can also make the transaction of payment a lot easier. For customers who perceive convenience, the electronic ordering system is easy to use and navigate. According to an online article, the advancement in information and communication technology (ICT) has significantly influenced the business transactions (Khairunnisa, Ayob, Helmy, Erdi, Ayob \& Ayob, 2009). It showed that with this technology, it can increase customer satisfaction to use the self-service kiosks in the context of easing the payment and resulting in increment sales for the quick service restaurant (QSR). Moreover, by using this self-service kiosk, it can help the customers who are cashless by making the payment with their credit card.

\section{Menu Design}

In the food service industry, menu is the most important selling tool and it can be in different forms printed, tablet, or menu kiosk. As for this study, a menu ordering by using kiosk technology was used. For a restaurant, the menu acts as guidance to the customers as they provide information about the foods and beverages served at the restaurant. The researchers decided to use the menu layout and colours used for graphics as the dimensions. Primarily in menu design, the layout of the menu should be taken into consideration. This is because the layout is one of the key components in the menu. Therefore, an apparent and clear-cut menu layout will provide a structured order that can help the customers to guide them through difficult information (Wang, 2012). The layout of the menu should be in the organized order and focuses on the main points for the customers to understand the menu efficiently. As Wang (2012) stated, the colour selection in menu design is also important to grab customer attention as it makes the text images appear more significant and remarkable. Besides, the use of colour for graphics is crucial in conveying and delivering messages to the customers. Psychologically some people tend to memorize easily when pictures and images used are colourful. Wang (2012) also added that the high quality and resolution of colours used not only get the customer's attention but also guide them to choose, strengthen the visual massage, accelerate the explanation, set up the mood, and justify the ideas.

\section{Order Accuracy}

Self-service kiosks can build up customer satisfaction by the increment of the accuracy orders. Order accuracy refers to the absence or minimal error that happened when the employees 
are serving the customer. The common method used in quick service restaurants (QSRs) when taking orders from the customers is that the staff are trained to repeat back to a customer's order before processing. By using this method, the error is still inevitable. Moreover, customers with disabilities issues such as hearing impaired and language barriers make it difficult to order the meal. For example, the pronunciation, diction, and hearing acuity issues are relevant to happen when using this method. Rastegar (2018) claimed that self-service kiosks can minimize errors and increase customer satisfaction by facilitating customized ordering. In addition, a visual recap of a customer's order increases the accuracy and puts the liability on the customers. Self-service kiosks allow the customers to place and pay for their orders easily, swiftly, and accurately. Customers with accessibility issues can also use this technology without any help from the employees or other people. Therefore, self-service kiosks can improve customer knowledge and experience.

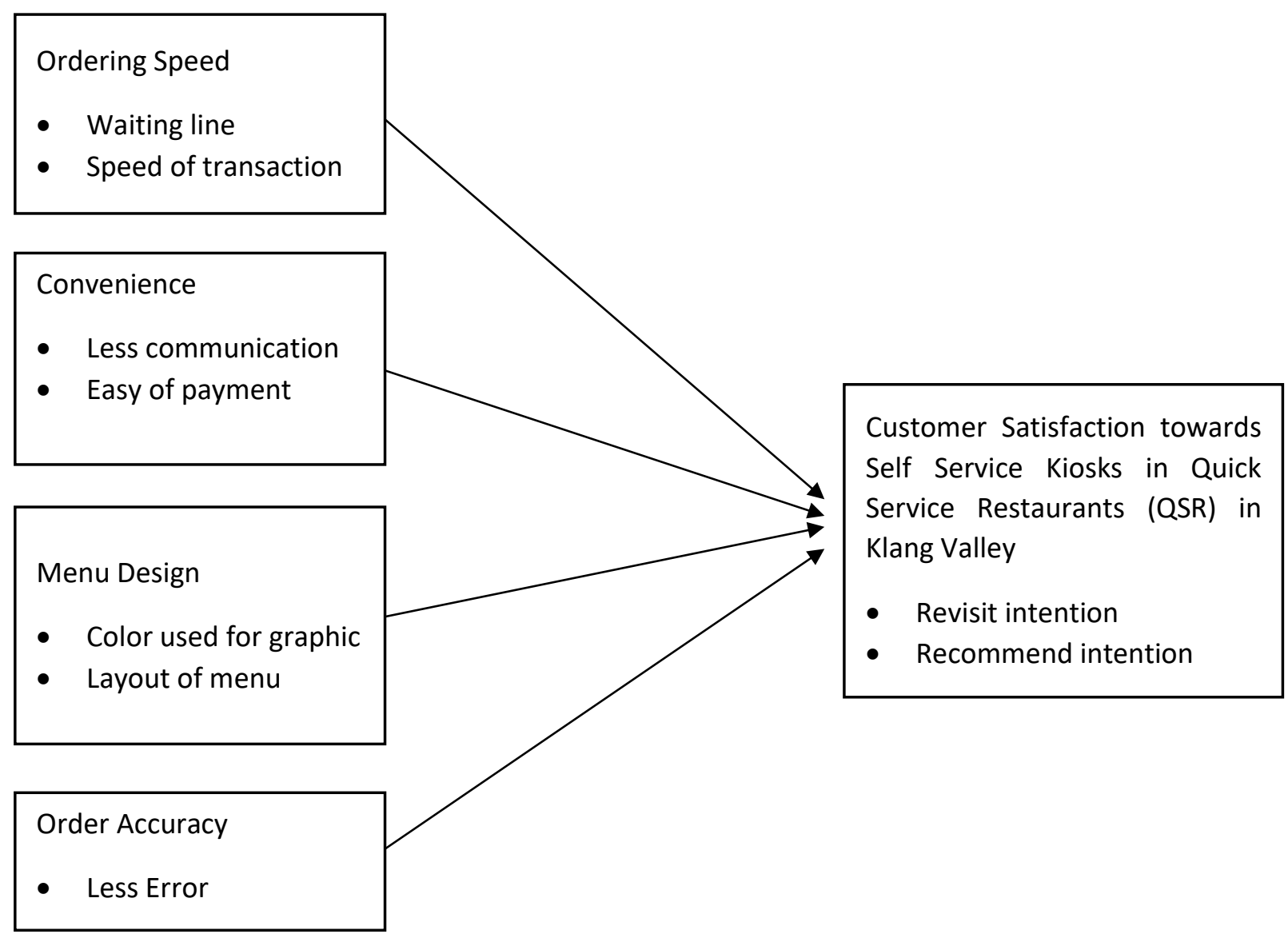

Figure 1: Proposed Research Framework

$\mathrm{H}_{1}$ : $\quad$ Ordering speed significantly influences customer satisfaction towards self-service kiosks for Quick Service Restaurants (QSRs) in Klang Valley.

$\mathrm{H}_{2}$ : $\quad$ Convenience significantly influences customer satisfaction towards self-service kiosks for Quick Service Restaurants (QSRs) in Klang Valley.

$\mathrm{H}_{3}$ : $\quad$ Menu design significantly influences customer satisfaction towards self-service kiosks for Quick Service Restaurants (QSR) in Klang Valley.

$\mathrm{H}_{4}$ : Order accuracy significantly influences customer satisfaction towards self-service kiosks for Quick Service Restaurants (QSRs) in Klang Valley. 


\section{Methodology}

The target population for this study was QSR customers who have experienced self-service kiosks in quick service restaurants (QSRs) in Klang Valley. The researchers only emphasized on quick service restaurants (QSRs) in particularly McDonald and Kentucky Fried Chicken (KFC) that have used self-service kiosks in their business operations. The questionnaire was adapted from various sources namely Lee (2008), Singh (2018), Ongori (2013), James (2014), Wang (2007) and Deel (2010). Based on the proposed model, this study used a quantitative research approach. An online questionnaire was created and developed on the online survey through Google Form. The questionnaire was divided into eight sections. Section A, B and C asked the respondents about their current location, their experience in using the self-service kiosk respectively and demographic area. For this section, the researchers were using nominal scale and ratio scale items. Meanwhile, in section $D, E, F, G$, and Section $H$, the respondents were asked on independent and dependent variables. Seven-point Likert Scale ranging from "strongly disagree", "disagree", "slightly disagree", "neutral", "slightly agree", "agree" and "strongly agree" was used for this section. Joshi, Kale, Chandel, and Pal (2015) stated in their study that the seven-point scale is more specific as it provides many choices compared to other scales.

\section{Data Collection Procedures}

For this study, a quantitative method was employed, and the researchers used primary data to carry out the questionnaires. Due to the outbreak of the pandemic Covid-19, the questionnaires were constructed and distributed in a form of an online survey on the Google Form. The respondents for this study were the customers who have experienced self-service kiosks in quick service restaurants (QSRs) in Klang Valley. Telegram, Facebook, and WhatsApp were the platforms that the researchers used to disperse the survey to the customers across Klang Valley. The data was collected within the duration of one month, and the researchers used Krejcia and Morgan's (1970) sample size table to determine the sample size. Considering the population of 40,000 , the suggested sample size is 380 respondents.

\section{Statistical Analysis}

All the data were analysed using IBM SPSS (version 25.0) software. These include analysis for demographic profile, descriptive statistics, factor analysis, reliability analysis to measure the consistency reliability of data collected and multiple linear regression to determine the relationship between customer satisfaction towards self-service kiosks with ordering speed, convenient, menu design and order accuracy.

\section{Result and Analysis Demographic Profiles}

Of 380 distributed questionnaires, merely 225 questionnaires (59.2\%) were usable and subjected to further statistical analyses whereas the balance of 155 questionnaires $(40.3 \%)$ were discarded due to missing data. As reported, 150 respondents were female (67\%) and 75 respondents were male (33\%). The respondent's age groups were divided into six categories which are below 18 years old, 19 until 25 years old, 26 until 35 years old, 36 until 45 years old, 46 until 59 years old, and above 60 years old. The mode of the age group was 19 until 25 years' old which made up $72.4 \%$ of the total respondents. For the marital status in this study, single respondents represented the highest percentage which are 184 respondents (82\%), 
and the remaining 41 respondents (18\%) are married. As for the ethnic group, Malay was the major respondent in this study, which is $94 \%$ follows by Indian in $4 \%$, and Chinese constituted for $2 \%$. In terms of employment status, $51 \%$ are the students and they contributed to the highest respondents in this category. It followed by the second-highest percentage which is the employees in the private sector $25 \%$, while the employees in the government sector and self-employed both shared the same percentage which is $8 \%$. The other $8 \%$ is made up of the employer, house-wife, retiree, and also unemployed. Lastly, the respondents of Shah Alam contributed $35 \%$ of the percentage and the remaining $65 \%$ came from the other part of Klang Valley.

Descriptive Analysis

Table 1.1: The Mean Score for Ordering Speed

\begin{tabular}{lccc}
\hline & Mean & Std. Deviation & N \\
\hline Ordering Speed Q1 & 6.27 & 1.276 & 225 \\
Ordering Speed Q2 & 6.08 & 1.372 & 225 \\
Ordering Speed Q3 & 6.27 & 1.247 & 225 \\
Ordering Speed Q4 & 6.23 & 1.214 & 225 \\
Ordering Speed Q5 & 6.28 & 1.201 & 225 \\
Ordering Speed Q6 & 6.23 & 1.271 & 225 \\
Ordering Speed Q7 & 6.24 & 1.302 & 225 \\
Ordering Speed Q8 & 6.06 & 1.397 & 225 \\
Ordering Speed Q9 & 5.97 & 1.442 & 225 \\
Ordering Speed Q10 & 6.27 & 1.333 & 225 \\
\hline
\end{tabular}

For the first Independent Variable which is Ordering Speed, the researchers focus on Customer Satisfaction on the waiting line and the transaction speed. From the data in the Table 1.1, it shows that Ordering Speed Q5 is the most agreed in this Independent Variable which resulted 6.28 of the mean. Most of the respondents agreed that the self-service kiosk handled the customer promptly. Meanwhile, the least mean score in this Independent Variable is Ordering Speed Q9 which is 5.97. Respondents are slightly agreed on the selfservice kiosk to perform the service at a designated time.

However, the researchers earned the same mean score for Ordering Speed Q1, Ordering Speed Q3, and Ordering Speed Q10. 
Table 1.2: The Mean Score for Convenience

\begin{tabular}{llll}
\hline & Mean & Std. Deviation & N \\
\hline Convenience Q1 & 5.81 & 1.320 & 225 \\
Convenience Q2 & 6.17 & 1.256 & 225 \\
Convenience Q3 & 6.18 & 1.314 & 225 \\
Convenience Q4 & 5.94 & 1.402 & 225 \\
Convenience Q5 & 6.14 & 1.325 & 225 \\
Convenience Q6 & 5.20 & 1.439 & 225 \\
Convenience Q7 & 6.06 & 1.247 & 225 \\
Convenience Q8 & 5.31 & 1.451 & 225 \\
Convenience Q9 & 5.94 & 1.232 & 225 \\
Convenience Q10 & 4.96 & 1.514 & 225 \\
\hline
\end{tabular}

The second Independent Variable is Convenience; whereas the items under Convenience are Customer Satisfaction on less communication and Customer Satisfaction on the ease of payment. The data in the Table 1.2 shows that the highest percentage of respondents agreed on Convenience Q3 in 6.18 which is "Self-service kiosk gives me control over my ordering" while the least mean score is Convenience Q10, which is 4.96 . The majority of respondents do not quite agree that they are not facing any problem while making a transaction at the self-service kiosk.

Table 1.3: The Mean Score for Menu Design

\begin{tabular}{llll}
\hline & Mean & Std. Deviation & N \\
\hline Menu Design Q1 & 5.70 & 1.362 & 225 \\
Menu Design Q2 & 4.93 & 1.568 & 225 \\
Menu Design Q3 & 5.81 & 1.285 & 225 \\
Menu Design Q4 & 5.77 & 1.253 & 225 \\
Menu Design Q5 & 5.72 & 1.210 & 225 \\
Menu Design Q6 & 5.87 & 1.256 & 225 \\
Menu Design Q7 & 6.16 & 1.276 & 225 \\
Menu Design Q8 & 5.67 & 1.282 & 225 \\
Menu Design Q9 & 5.51 & 1.320 & 225 \\
Menu Design Q10 & 5.92 & 1.317 & 225 \\
\hline
\end{tabular}

For Menu Design, the Independent Variables are divided into two items which are Customer Satisfaction on the colour of the menu and the layout of the menu. Table 1.3 shows the highest mean for Menu Design which is Menu Design Q7 (6.16). This indicates that the Menu Design on the self-service kiosk is more organized than the Menu Design displayed on the board at the back of the counter. On the other hand, the lowest mean in this Independent Variable is Menu Design Q2 (4.93) where the respondents do not agree that the colour of the menu on the self-service kiosk is appealing for them. 
Table 1.4: The Mean Score for Order Accuracy

\begin{tabular}{llll}
\hline & Mean & Std. Deviation & N \\
\hline Order Accuracy Q1 & 5.61 & 1.355 & 225 \\
Order Accuracy Q2 & 5.67 & 1.243 & 225 \\
Order Accuracy Q3 & 5.32 & 1.303 & 225 \\
Order Accuracy Q4 & 5.36 & 1.408 & 225 \\
Order Accuracy Q5 & 5.00 & 1.685 & 225 \\
\hline
\end{tabular}

The last independent variable in this study is Order Accuracy and the item under this study is minimizing error. Table 1.4 illustrates the result of respondents for Order Accuracy. The top mean score in this variable is Order Accuracy Q2 (5.67) which most of the respondents agreed that the self-service kiosks accurately verified their ordering. Nevertheless, the respondents slightly agreed on Order Accuracy Q5 (5.00) which is a self-service kiosk performed their service for the first time experience.

Table 1.5: The Mean Score for Customer Satisfaction towards Self-Service Kiosks

\begin{tabular}{lllll}
\hline & Mean & Std. Deviation & N \\
\hline $\begin{array}{l}\text { Customer } \\
\text { Q1 }\end{array}$ & Satisfaction & 5.94 & 1.272 & 225 \\
$\begin{array}{l}\text { Customer } \\
\text { Q2 }\end{array}$ & Satisfaction & 5.84 & 1.184 & 225 \\
$\begin{array}{l}\text { Customer } \\
\text { Q3 }\end{array}$ & Satisfaction & 6.14 & 1.202 & 225 \\
$\begin{array}{l}\text { Customer } \\
\text { Q4 Satisfaction }\end{array}$ & 6.17 & 1.196 & 225 \\
$\begin{array}{l}\text { Customer } \\
\text { Q5 }\end{array}$ & Satisfaction & 6.14 & 1.258 & 225 \\
\hline
\end{tabular}

Customer Satisfaction towards self-service kiosks is the Dependent Variable for this study. Table 1.5 stated that most of the respondents have the same view on Customer Satisfaction Q4 (6.17) where there is a high likelihood that they would recommend the self-service kiosks to their friend and colleagues. For Customer Satisfaction Q3 and Q5, the data provides the same result which is 6.14. Last but not least, the smallest amount of mean scored is Customer Satisfaction Q2 (5.84) which the self-service exceeded their expectation.

\section{Factor Analysis}

Table 1.6: SPSS output KMO and Bartlett's Test

\begin{tabular}{lll}
\hline KMO and Bartlett's Test & & \\
\hline Kaiser-Meyer-Olkin Measure of Sampling Adequacy. & .936 \\
Bartlett's Test of Sphericity & Approx. Chi-Square & 10630.250 \\
& Df & 595 \\
& Sig. & .000 \\
\hline
\end{tabular}


Based on the Table 1.6, there is an adequate correlation between the variables to proceed since the KMO is 0.936 and Bartlett's Test of Sphericity is Sig. $=0$, while statistical significance is $p>0.05$. Besides, four (4) components extracted as the value of eigenvalues is greater than 1.0. The percentage of variance for each Independent Variable on Ordering Speed is $27.45 \%$, Menu Design $=22.32 \%$, Order Accuracy $=14.79 \%$ and Convenience $=14.05 \%$. These four (4) components solutions point out a total of $78.61 \%$ variances explained. Ordering Speed has the highest loading factor, followed by Menu Design, Order Accuracy, and lastly the Convenience. This is not considering whether the correlation is positive or negative.

\section{Reliability Analysis}

Table 1.7: Summary table for Cronbach's Alpha based on SPSS Output

\begin{tabular}{lcc}
\hline Variables & Cronbach's Alpha & $\begin{array}{c}\text { No. of } \\
\text { Questions }\end{array}$ \\
\hline Ordering speed & 0.977 & 10 \\
Convenience & 0.933 & 10 \\
Menu design & 0.960 & 10 \\
Order Accuracy & 0.925 & 5 \\
Customer Satisfaction Toward Self-service Kiosk & 0.965 & 5 \\
\hline
\end{tabular}

Generally, Cronbach's Alpha main purpose is to find the objectives on how to measure the consistency reliability of the data collected. Olaniyi (2019) said that the values for Cronbach's Alpha are between 0.0 until 1.0. The value of 0 indicates that there is no consistency in the measurement meanwhile value 1.0 means a perfect consistency in the measurement. Furthermore, the consistency between 0.70 and 0.90 usually among the acceptance range. Based on the Table 1.7, all the variables are reliable and consistent with each other as all the values for Cronbach's Alpha above 0.9, which indicates a good value.

\section{Multiple Linear Regressions}

Multiple linear regression analysis is used to explain the relationship between one Dependent Variable and two or more Independent Variables (Bevans, 2020). There is no multicollinearity was found between the variables since all the tolerance and Variance Inflation Factor (VIF) for variables has met the variables tolerances which are more than 0.2 and the Variance Inflation Factor (VIF) is lesser than 10. Next, these variables are also free from autocorrelation as the Durbin-Watson statistic result shows 1.917, and this has reflected an acceptable result.

The Coefficient of Determination $\left(R^{2}\right)$ indicates the proportion of variance in the Dependent Variables that are explained by the Independent Variable (Corporate Finance Institute, 2020). The Dependent Variable which is the Customer Satisfaction towards self-service kiosks is explained $67.9 \%\left(R^{2}=0.679\right)$ of all Independent Variables, Ordering Speed, Convenience, Menu Design, and Order Accuracy. Next, ANOVA also showed the overall regression model which is appropriate as $\mathrm{F}=116.206$, Sig=0, and the significance value is less than 0.05 . 
Tables 1.8: Summary of Multiple Linear Regressions from SPSS Output

\begin{tabular}{lccc}
\hline & B & Std. Error & Sig. \\
\hline (Constant) & .533 & .268 & .048 \\
Ordering Speed & .184 & .050 & .000 \\
Convenience & .180 & .063 & .005 \\
Menu Design & .378 & .062 & .000 \\
Order Accuracy & .219 & .051 & .000 \\
\hline
\end{tabular}

By looking at the significant levels, this study established a significant relationship between Customer Satisfaction towards self-service kiosks and all the Independent Variables which are the Ordering Speed $(p=0.00 ; t=3.692)$, Convenience $(p=0.005 ; t=2.852)$, Menu Design $(p=0.000 ; t=6.104)$, and Order Accuracy $(p=0.000 ; t=4.338)$. These Independent Variables are significant with the Dependent Variable as the sig. value is less than 0.05. Next, unstandardized coefficients represent the amount by which the Dependent Variable changes if the Independent Variable changes by one unit keeping other Independent Variables constant (Bhalla, 2015). The equation for Customer Satisfaction towards self-service kiosks in Quick Service Restaurants (QSRs) at Klang Valley is shown below:

Customer Satisfaction towards Self Service Kiosks in Quick Service Restaurants (QSRs) at Klang Valley $=0.533+0.184$ (Ordering Speed) +0.180 (Convenience) +0.378 (Menu Design) +0.219 (Order Accuracy)

This equation means that 1 unit increases in Ordering Speed will increase Customer Satisfaction towards self-service kiosks in Quick Service Restaurants (QSRs) at Klang Valley by 0.183. It also applies for the second Independent Variable where 1 unit increases in Convenience, Customer Satisfaction towards self-service kiosks in Quick Service Restaurants (QSRs) at Klang Valley will increase by 0.180.

Next, Menu Design seems to be the most influential factor as a 1 unit increases in Menu Design will increase Customer Satisfaction towards self-service kiosks in Quick Service Restaurants (QSRs) at Klang Valley by 0.378. Moreover, 1 unit increases in Order Accuracy, Customer Satisfaction towards self-service kiosks in Quick Service Restaurants (QSRs) at Klang Valley also will increase by 0.219 . Hence, all the Independent Variables are giving a positive impact on Customer Satisfaction towards self-service kiosks in Quick Service Restaurants (QSRs) at Klang Valley.

\section{Discussion}

Based on the first hypothesis $\left(\mathrm{H}_{1}\right)$, Ordering Speed significantly influences Customer Satisfaction towards self-service kiosks for Quick Service Restaurants (QSRs) was accepted. This is because the significance level falls on $p=0.0, t=3.692$ which is the accepted level. Besides, the coefficient is 0.184 . Hence, there is a positive relationship between Ordering Speed and Customer Satisfaction toward self-service kiosks in Quick Service Restaurants (QSRs) in Klang Valley.

The result achieved from this finding indicates that the respondents were satisfied with the Ordering Speed when using the self-service kiosks in Quick Service Restaurants (QSRs). This 
Ordering Speed includes the process of ordering using self-service kiosks, the payment process and the time for the food to be served. The customers want these processes to be fast so that they do not have to wait for a long time. Shorter waiting time and shorter queuing lines will influence and encourage the customers to revisit the restaurant. This finding was supported by a study from Polas, Rahman, Miah, and Hayash (2018) which stated that the customers usually do not like to wait for a long time to receive the service as they tend to become impatient. They continued that Customer Satisfaction placed first through the waiting time satisfaction as compared to the others. The waiting time is related to Ordering Speed, hence, this shows that it is an important factor to satisfy the customers who use selfservice kiosks in Quick Service Restaurants (QSRs) in Klang Valley.

For the Convenience Variable, the coefficient result is 0.180 along with the significance level that falls on $p=0.005, t=2.852$. Thus, there has a positive relationship between Convenience and Customer Satisfaction towards self-service kiosks in Quick Service Restaurants (QSRs) at Klang Valley. Therefore, the result explained that the respondents were satisfied with the Convenience of the self-service kiosks as compared with the counter service. There were two dimensions for Convenience which are less communication and ease of payment. For less communication, respondents prefer to use self-service kiosks due to the comfort and space given to them compared to counter service. Whilst, for the ease of payment, the respondents tended to use the self-service kiosks due to the Convenience as they can monitor the transaction at the same time. In a study by Kimes (2011), it stated that the Perceived Convenience of self-service systems can increase Customers' Satisfaction. Thus, this indicates that Convenience is essential to achieve Customer Satisfaction in Quick Service Restaurants (QSRs).

Next, the researchers wanted to observe Customer Satisfaction through the design of the selfservice kiosk itself. The data stated in the statistical analysis shows a positive relationship between the Menu Design and Customer Satisfaction towards self-service kiosks in Quick Service Restaurants (QSRs) in Klang Valley at $p=0.0, t=6.104$. This outcome shown that most of the respondents were satisfied with the Menu Design in the self-service kiosk. In this variable, two items listed under the Menu Design which were the colour of the menu and Customer Satisfaction on the layout of the menu. In most cases, the majority of people are interested to see something that attracts their eyes. The self-service kiosk is a modern technology with a good design that will attract customers to use them. This finding was supported by the study conducted by Wang (2012) that stated an image can easily catch customer attraction and read promptly by looking at the pattern of the menu. Thus, the image of the menu selected should be in high quality to attract the customers' attention.

Beside the image of the menu, the pictures and graphics of the menu at the self-service kiosk should also be perfect and clear. The respondents were also satisfied with the layout provided on the self-service kiosk. A great layout of a completed menu and detailed description boosted up their mood in choosing their order. Supporting to this, Wang (2012) also said that the selection colour of the menu design is crucial to grab customer's attention. In short, the Menu Design of self-service kiosks is one of the factors that brings Customer Satisfaction towards self-service kiosks in Quick Service Restaurants (QSRs). 
Lastly, there was a positive relationship between Order Accuracy and Customer Satisfaction towards self-service kiosks in Quick Service Restaurants (QSRs) at Klang Valley as the statistical result shows a coefficient which at 0.219 and a significant level at $p=0.0, t=4.338$. This finding shown that most of the respondents were satisfied with the accuracy of order when they were using self-service kiosks in Quick Service Restaurants (QSRs). Most of the respondents also acknowledged and satisfied with self-service kiosks as it can accurately verify the orders and increase respondents' effectiveness during food ordering. Moreover, most of the respondents can utilize the self-service kiosks without any error or mistake even on their first attempt. This finding was supported by a study conducted by Fernandes and Pedroso (2016) where it stated that the reliability or accuracy of service is considered the most important determinant of self-service quality, and it is accurately a source of customer satisfaction (p. 91). A study stated that the respondents had evaluated the restaurant technology as a big helper to increase Order Accuracy (Rastegar, 2018). Hence, Order Accuracy is one of the factors that influence Customer Satisfaction towards self-service kiosks in Quick Service Restaurants (QSRs) in Klang Valley.

\section{Conclusion}

This study has shown that most of Klang Valley residents are satisfied with the implementation of self-service kiosks in Quick Service Restaurants (QSRs) as it may increase the ordering speed, develop convenient, understandable, and attractive menu design, and enhance order accuracy. However, there are few suggestions and recommendations for future research that can produce a better result. The first recommendation is a balanced number of respondents for demography. It is advised for future research to gain a balanced number of respondents in demography to represent the overall population. In this study, most of the respondents were female and for the ethnic, the majority of respondents were young since most of them were students. Therefore, different ethnicities, ages, and gender might have influenced their perspective and satisfaction towards the self-service kiosks. For example, the younger respondents are quite familiar with the technology as they always utilize it on their daily basis, meanwhile the elder customers might not familiar and refuse the technology. Second suggestion is to broaden the population of the study as the researchers only focused on customers in Klang Valley; which is one of the urban conurbations in the central Selangor, Malaysia. The customers that are located in other locations may lead to different outcomes and satisfaction towards self-service technology, especially the rural areas. Most of the customers from Klang Valley are well exposed to technology meanwhile the customers from rural areas are less exposed to this technology development. Apart from that, there is still a small number in studies or researches made from the employer's and employee's perspectives regarding self-service kiosks or other self-service technology in the hospitality industry. Finally, as the study shown that most customers were satisfied with selfservice kiosks, the government should encourage the public to use self-service kiosks, especially during this COVID-19 situation. With self-service kiosks, the interaction between service staff and customers can minimize and reduce the possibility of COVID-19 infection.

\section{Corresponding Author}

Zurena@Rena Shahril. Faculty of Hotel and Tourism Management, Universiti Teknologi MARA, Puncak Alam Campus, 42300, Puncak Alam, Selangor, Malaysia.

Email: zurena511@uitm.edu.my 


\section{References}

Abdullah, D., Hamir, N., Nor, N. M., Krishnaswamy, J., \& Rostum, A. M. M. (2018). Food quality, service quality, price fairness and restaurant re-patronage intention: The meditating role of customer satisfaction. International Journal of Academic Research in Business and Social Sciences, 8(17), 211-226.

Akhtar, I. (2016). Research design. SSRN Electronic Journal, 68-84. https://doi.org/10.2139/ssrn.2862445

Asaolu, H. (2017). 5 Technology concepts to reduce costs for your business. Retrieved from https://www.business2community.com/business-innovation/5-technology-conceptsreduce-costs-business-01826059

Benefits of Self-Service Kiosks in QSR and Restaurants | Frank Mayer. (2020, February 7). Retrieved from https://www.frankmayer.com/whitepapers/key-benefits-of-utilizingself-service-kiosks-in-quick-service-and-fast-casual-restaurants/

Bevans, R. (2020). An introduction to multiple linear regression. Scribbr. https://www.scribbr.com/statistics/multiple-linear-regression/

Bhalla, D. (2015). Standardized vs Unstandardized Regression Coefficient. ListenData. https://www.listendata.com/2015/04/standardized-vs-unstandardized.html

Çalışkan, H. K. (2015). Technological change and economic growth. Procedia - Social and Behavioural Sciences, 195, 649-654. https://doi.org/10.1016/j.sbspro.2015.06.174

Chang, M. (2015). Perceived factors influencing the acceptance and adoption of self-service technology. (Master dissertation/thesis, UTAR).

http://eprints.utar.edu.my/id/eprint/1621

Comscore, Inc. (2019). State of Retail. Retrieved April 15, 2020, from https://www.comscore.com/Insights/Presentations-and-Whitepapers/2019/State-ofRetail

Corporate Finance Institute. (2020, April 30). Adjusted R-squared. https://corporatefinanceinstitute.com/resources/knowledge/other/adjusted-rsquared/

Corporate Finance Institute. (2020b). Coefficient of determination. https://corporatefinanceinstitute.com/resources/knowledge/other/coefficient-ofdetermination/

Deel, G. (2010). Exploring the association of the attributes of self-service kiosks, customer check-in

satisfaction, and customer commitment in convention hotels: The case of the Rosen Centre Hotel, A convention hotel.

Dillard, J. (2017). The data analysis process: 5 steps to better decision making. Bigsky associates.https://www.bigskyassociates.com/blog/bid/372186/The-Data-AnalysisProcess-5-Steps-To-Better-Decision-Making

Eilers, G. M. (2004). Improving patient satisfaction with waiting time. Journal of American College Health, 53(1), 41-48. https://doi.org/10.3200/jach.53.1.41-48

Fernandes, T., and Pedroso, R. (2016). The effect of self-checkout quality on customer satisfaction and repatronage in a retail context. Service Business, 11(1), 69-92. https://doi.org/10.1007/s11628-016-0302-9

Hayes, A. (2019). Simple random sample. Retrieved April 15, 2020, from https://www.investopedia.com/terms/s/simple-random-sample.asp 
Ismail, Z., \& Shokor, S. S. A. (2016). The application of waiting lines system in improving customer service management: The examination of Malaysia fast food restaurants industry. In IOP Conference Series: Earth and Environmental Science (Vol. 32, No. 1, p. 012074). IOP Publishing

James, K. K. (2014). Exploration of user satisfaction with retail self-service technologies. A thesis submitted to the Faculty of the Graduate School of the University of Minnesota

Jasonos, M., \& McCormick, R. (2017). Theseus: Technology integration for restaurants and hospitality industry in the Year 2025. Retrieved from https://www.theseus.fi/handle/10024/132779

Joshi, A., Kale, S., Chandel, S., \& Pal, D. K. (2015). Likert scale: Explored and explained. British Journal of Applied Science and Technology, 7(4): 396-403, 2015, Article no.BJAST.2015.157

Kazandzhieva, V., Ilieva, G., Student, H., \& Filipova. (2017). The impact of technological innovations on hospitality service. Presented at the contemporary tourism - traditions and innovations, Sofia University, "St. Kliment Ohridski."

Khairunnisa, K., Ayob, J., Helmy, A. W. M., Erdy, A. M., Ayob, M. I., \& Ayob, M. A. (2009). The application of wireless food ordering system (2nd ed., Vol. 1). Batu Pahat, Johor: MASAUM. Journal of Computing, University Tun Hussein Onn.

Kimes, S. E. (2011). Customer perceptions of electronic food ordering [Electronic article]. Cornell Hospitality Report, 11(10), 6-15.

Kokkinou, A., and Cranage, D. A. (2015). Why wait? Impact of waiting lines on self-service technology use. International Journal of Contemporary Hospitality Management, 27(6), 1181-1197. https://doi.org/10.1108/ijchm-12-2013-0578

Krejcie, R. V., and Morgan, D. W. (1970). Determining sample size for research activities. Educational and Psychological Measurement, 30(3), 607-610. https://doi.org/10.1177/ 001316447003000308

Kumar, M., Talib, S. A., \& Ramayah, T. (2013). Business Research Methods (1st ed.). Oxford University Press.

Lee, H. J. (2008). Technology-based self-service kiosks in retailing: An optional channel for customer service. Trace: Tennessee research and creative exchange.

Martínez-Mesa, J., González-Chica, D. A., Duquia, R. P., Bonamigo, R. R., \& Bastos, J. L. (2016). Sampling: how to select participants in my research study? Anais Brasileiros de Dermatologia, 91(3), 326-330. https://doi.org/10.1590/abd1806-4841.20165254

Meuter, M. L., Ostrom, A. L., Roundtree, R. I., \& Bitner, M. J. (2000). Self-service technologies: Understanding customer satisfaction with technology-based service encounters. Journal of Marketing, 64(3), 50-64.

https://doi.org/10.1509/jmkg.64.3.50.18024

Ograjensek, I., \& Gal, I. (2012). The concept and assessment of customer satisfaction. Modern analysis of customer surveys: with applications using R, First Edition. John Wiley \& Sons.

Olaniyi, A. A. (2019). Application of Likert scale's type and Cronbach's alpha analysis in an airport perception study. Scholar Journal of Applied Sciences and Research.

Ongori, M. H. (2013). Self-service technology and customer satisfaction in commercial banks in Kenya. A Management research project submitted in partial fulfilment of the requirement for the award of Master of Business Administration, School of Business, University of Nairobi. 
Pavesic, D. (2005). The psychology of menu design: Reinvent your 'Silent Salesperson' to increase check averages and guest loyalty. Hospitality Faculty Publications. Paper 5.

Plecher, H. (2020). Malaysia - employment by economic sector. Retrieved April 15, 2020, from https://www.statista.com/statistics/319036/employment-by-economic-sector-inmalaysia/

Polas, M. R. H., Rahman, M. M., Miah, M. A., \& Hayash, M. M. A. (2018). The impact of waiting time towards customers' satisfaction in fast food establishments: Evidence from Bangladesh. Journal of Business and Management.

Rastegar, N. (2018). Adoption of Self-service Kiosks in Quick-service Restaurants. Presented at the TTRA Canada 2018 Conference, University of Massachusetts Amherst.

Robertson, N., McDonald, H., Leckie, C., \& McQuilken, L. (2016). Examining customer evaluations across different self-service technologies. Journal of Services Marketing, 30(1), 88-102. https://doi.org/10.1108/jsm-07-2014-0263

Sawe, B. E. (2018). What are the biggest industries in Canada? Retrieved from https://www.worldatlas.com/articles/what-are-the-biggest-industries-in-canada.html

Shaharudin, M. R., Mansor, S. W., \& Elias, S. J. (2011). Food quality attributes among Malaysia's fast food customer. International Business and Management, 198-208. https://doi.org/10.3968/j.ibm.1923842820110201.015

Simon, M. K., \& Goes, J. (2011). Correlational research. Retrieved from http://dissertationrecipes.com/wp-content/uploads/2011/04/CorrelationalResearchX.pdf.

Singh, A. (2018). Self-service technologies at airports evaluating passengers' perceived service quality towards self-service luggage check-in technologies at airports using SSTQUAL scale.

Sumathi, N., Vishnu, S. A., Govindan, G., Sreekumar, M., Srinivas, N., \& Siddarth, Y. S. (2017). Business analysis of a food restaurant chain. International Journal of Latest Technology in Engineering, Management \& Applied Science.

Tan, L. Y. (2016). Fast Food Consumption Behaviour Among Generation Y in Malaysia. Retrieved from http://eprints.utar.edu.my/2231/

Tariq, Q. (2019). KFC introduces self-service kiosks in Klang Valley. The Star Online. https://www.thestar.com.my/tech/tech-news/2019/05/06/kfc-introduces-selfservice-kiosks-in-klang-valley

Ursachi, G., Horodnic, I. A., \& Zait, A. (2015). How reliable are measurement scales? External factors with indirect influence on reliability estimators. Procedia Economic and Finance.

Vogli, R. D., Kouvonen, A., \& Gimeno, D. (2013). The Influence of market deregulation on fast food consumption and body mass index: A cross-national time series analysis.

Wang, J. (2007). Technology-based self-service and its impact on service firm performance.

Wang, Y. (2012). Designing restaurant digital menus to enhance user experience. Graduate theses and dissertations. 12781.

Wang, Y., Wang, L., Xue, H., \& Qu, W. (2016). A review or the growth of the fast food industry in China and its potential impact on obesity. International Journal of Environmental Research and Public Health.

Whitting, B. (2016), "What is data analysis? - Definition \& overview", Retrieved from https://study.com/academy/lesson/what-is-data-analysis-definition-overview.html. 
Yieh, K., Chen, J., \& Wei, M. B. (2012). The effects of technology readiness on customer perceived value: An empirical analysis. Journal of Family and Economic Issues, 33(2), 177-183. https://doi.org/10.1007/s10834-012-9314-3

Yong, A. G., \& Pearce, S. (2013). A beginner's guide to factor analysis: Focusing on exploratory factor analysis. Tutorials in quantitative method for psychology.

Yong, C. K., Siang, D. O. C., Lok, T. W., \& Kuan, W. Y. (2013). Factors influencing dining experience on customer satisfaction and revisit intention among undergraduates towards fast food restaurants. 